\title{
Effects of Dietary Fiber on Gastrointestinal Transit Time, Fecal Properties and Fat Absorption in Rats
}

\author{
Akiniro Munakata, Satoru Ifane, Masahiro Todate, \\ Shigeyuki Nakaji* and Kazuo Sugawara* \\ The First Department of Internal Medicine, and \\ * Department of Hygiene, Hirosaki University School of \\ Medicine, Hirosaki 036
}

\begin{abstract}
Munakata, A., Iwane, S., Todate, M., Nakaji, S. and Sugawara, K. Effects of Dietary Fiber on Gastrointestinal Transit Time, Fecal Properties and Fat Absorption in Rats. Tohoku J. Exp. Med., 1995, 176 (4), 227-238 — The gastrointestinal transit time of food was determined by $\mathrm{x}$-ray fluoroscopy using barium sulfate in rats fed with diets of various dietary fiber contents, and the effects of dietary fiber on the transit time, properties of feces, and fat absorption were examined. In 4- and 16-month-old rats fed with the diet for 3 and 15 month, respectively, the transit time of the cecum and colon in those receiving 20 and $40 \%$ wheat bran diets was shortened compared with that in the $0 \%$ group. The fecal pellet number and volume increased as the wheat bran content of the diet increased. In another experiments, the daily total fat excretion was found to be the greatest in rats receiving $15 \%$ pectin diet, followed by rats receiving $15 \%$ cellulose and non-fiber diets, respectively. These results suggest that shortening of the transit time through the cecum and colon with increase of fecal volume and suppression of fat absorption all participate in the mechanism of the inhibitory action of wheat bran on carcinogenesis and on the development of diverticulum of the large intestine. dietary fiber; wheat bran; transit time
\end{abstract}

The effects of dietary fiber (DF) on gastrointestinal function, which have been described in many reports, include its action in shortening the gastrointestinal transit time of food, especially large intestine transit time, which has received attention as a major factor for the development of colonic carcinomas, and also for the development of diverticulum in the large intestine (Burkitt 1971; Burkitt et al. 1972). In the present study, we measured the transit time of food through each of the esophagus, stomach, and small and large intestine in rats fed with wheat bran by x-ray fluoroscopy using barium sulfate to examine the effects of dosage and administration period of wheat bran on the transit time. The changes in fecal properties induced by wheat bran administration and the effects of pectin

Received March 10, 1995; revision accepted for publication May 10, 1995.

Address for reprints: Shigeyuki Nakaji, Department of Hygiene, Hirosaki University School of Medicine, 5 Zaifu-cho, Hirosaki 036, Japan. 
and cellulose on fat absorption were also studied.

\section{Materials And Methods}

Rats aged 4 and 16 months were used in this study. Beginning at four weeks of age, all rats were given pulverized chow (Oriental Yeast Co., Ltd., Tokyo) together with wheat bran at a concentration (weight \%) of 0,20 or $40 \%$ (control, 20 and $40 \%$ diet, respectively). The rats were classified into the six groups (Groups A-F) shown in Table 1. The content of the pulverized diet is shown in Table 2; the diet has been found to contain $9.0 \%$ dietary fiber measured by Van Soest's method (Van Soest and Wine 1967).

\section{Gastrointestinal transit time}

Rats in Groups A and D were used for measurement of gastrointestinal transit time. After 20-hr fast, the rats were given control diet, together with diet containing barium sulfate for $15 \mathrm{~min}$ ( 65 weight $\%$ ), followed by the respective diet without the barium sulfate for $15 \mathrm{hr}$. $\mathrm{x}$-Ray fluoroscopy was used to measure the gastrointestinal transit time of the barium diets. Each transit time was determined by calculating the difference between the time point at which the

TABLE 1. Rat groups

\begin{tabular}{cccc}
\hline \multirow{2}{*}{ Age (month) } & \multicolumn{3}{c}{ Wheat bran \% } \\
\cline { 2 - 4 } $4\left(3^{\mathrm{a}}\right)$ & 0 & 20 & 40 \\
$16(15)$ & $\mathrm{A}\left(17^{\mathrm{b}}\right)$ & $\mathrm{B}(17)$ & $\mathrm{C}(17)$ \\
& $\mathrm{D}(13)$ & $\mathrm{E}(13)$ & $\mathrm{F}(13)$ \\
\hline
\end{tabular}

a Duration of experimental diet (months)

${ }^{b}$ Number of rat

TABLE 2. Composition of pulverized diet

\begin{tabular}{lc}
\hline \multicolumn{1}{c}{ Component } & $\mathrm{g} / 100 \mathrm{~g}^{\mathrm{a}}$ \\
\hline Corn starch & 46 \\
Casein (Vitamin free) & 25 \\
$\alpha$-Starch & 10 \\
Vegetable oil & 6 \\
Minerals & 6 \\
Granulated sugar & 5 \\
Vitamins & 2 \\
Dietary fiber & 9 \\
\hline
\end{tabular}

${ }^{\text {adry }}$ weight

${ }^{\mathrm{b}}$ Dietary fiber was measured by Van

Soest's method. 
leading edge of the barium medium arrived at the esophagus, stomach, and small and large intestine, respectively. The large intestine transit time was divided into the following three subunits: the cecum transit time, defined as the period from the beginning of flow of the barium medium into the cecum until its beginning of flow into the colon; the colon transit time, the period from the beginning of flow of the barium medium into the colon until its arrival at the rectum; and the rectum transit time, the period from the beginning of flow of the barium medium into the rectum until defecation. Further, the gastrointestinal transit time of the same rat was measured using $20 \%$ and $40 \%$ diet instead of control diet by same method.

Further, the gastrointestinal transit time was also measured in rats in Groups $\mathrm{D}, \mathrm{E}$ and $\mathrm{F}$ fed with the barium diet together with the control diet to examine the effect of longer-term dietary exposure on the transit time. During $\mathrm{x}$-ray fluoroscopy, the rats were placed in a paper box $(30 \times 15 \times 15 \mathrm{~cm})$ and given water and food ad libitum.

Number, weight, water content and volume of feces

The number, weight, water content and volume of feces were examined in rats in Groups A, B and C. After fasting for $20 \mathrm{hr}$, the rats in each group were given 0, 20 and $40 \%$ diets for $16 \mathrm{hr}$, respectively. The number of fecal pellets excreted during the $16-\mathrm{hr}$ period was counted, and the feces after each defecation were weighted. Each fecal specimen was then lyophilized and weighed to determine the water content. The fecal volume was determined by rapidly transferring the feces obtained just after defecation into a glass cylinder ( $8 \mathrm{~mm}$ inner diameter) filled with water and then measuring the elevation of the water surface.

\section{Fat absorption}

Non-fiber diet (Oriental Yeast Co, Ltd., Tokyo; the composition is shown in Table 3 ), $15 \%$ pectin diet ( $15 \%$ pectin with $85 \%$ non-fiber diet; weight $\%$ ), or $15 \%$ cellulose $\operatorname{diet}(15 \%$ cellulose with $85 \%$ non-fiber diet; weight $\%$ ), was given to Group D rats, and the daily fat excretion per gram of dried stool and total daily fat excretion were determined by Van de Kamer's method (Van de Kamer 1949).

TABLE 3. Composition of non-DF diet

\begin{tabular}{lc}
\hline Component & $\mathrm{g} / 100 \mathrm{~g}^{\mathrm{a}}$ \\
\hline Rice dextrin & 70 \\
Rice oil & 9 \\
Casein & 15 \\
Minerals & 3 \\
Vitamins & 3 \\
\hline
\end{tabular}

adry weight 


\section{Statistical method}

The data obtained were statistically analyzed using Student's $t$-test. A $p$ value of less than 0.05 was regarded as significant.

\section{RESUlts}

\section{Gastrointestinal transit time}

Fig. 1a shows x-ray fluoroscopic images showing the transit of the contrast diet through the esophagus of a rat. The esophageal transit time was about one second. The contrast medium was retained in the stomach for 2-3 min, and then expelled into the small intestine, as shown in Fig. 1b. The small intestine transit time did not exceed about two hours. The contrast diet rapidly entered the cecum, where it remained (Fig. 1c), and then entered the colon and assumed the shape of feces. The feces moved through the large intestine and the rectum and were finally excreted by defecation (Fig. 1d). The feces were retained in the rectum for a relatively long time; the retention time in the rectum comprised more than half of the large intestine transit time in almost all rats. Several feces were simultaneously excreted in many cases.

The gastrointestinal transit time in rats aged 4 months is summarized in Table 4. In 4-month old rats, there were no significant differences among the three diet groups in the stomach or small intestine transit time, while the cecum transit time in the $20 \%(57 \pm 10 \mathrm{~min})$ and $40 \%(54 \pm 15 \mathrm{~min})$ diet groups was significantly shorter than the transit time of $67 \pm 15 \mathrm{~min}$ in the control diet group (both, $p<$ 0.05). The colon transit time in the $40 \%$ diet group $(50 \pm 10 \mathrm{~min})$ was significantly shorter than that in the control $(66 \pm 10 \mathrm{~min})$ and the $20 \%(60 \pm 8$ min) diet group (both, $p<0.01$ ). The rectum transit time showed large standard deviations in all groups. The gastrointestinal transit time in the 16-month-old rats (Table 5) was simiar to that in the 4-month-old rats; the stomach transit time and small intestine transit time were comparable in the three diet groups, and the

TABLE 4. Gastrointestinal transit time in rats aged 4 months (Group A)

\begin{tabular}{|c|c|c|c|c|c|c|c|c|c|}
\hline \multirow{2}{*}{$\begin{array}{c}\text { Wheat bran } \\
(\%)\end{array}$} & \multicolumn{9}{|c|}{ Transit time $(\min )$} \\
\hline & Stomach & $\begin{array}{c}\text { Small } \\
\text { intestine }\end{array}$ & Cecum & & Colon & & & Rectum & Total \\
\hline $\begin{array}{c}0 \\
(n=17)\end{array}$ & $3 \pm 1^{a}$ & $91 \pm 15$ & $67 \pm 15$ & * 7 & $66 \pm 13$ & & & $144 \pm 90$ & $371 \pm 100$ \\
\hline $\begin{array}{c}20 \\
(n=17)\end{array}$ & $3 \pm 1$ & $90 \pm 18$ & $57 \pm 10$ & & * $\quad 60 \pm 87$ & $* *$ & $* *$ & $171 \pm 95$ & $381 \pm 84$ \\
\hline $\begin{array}{c}40 \\
(n=17)\end{array}$ & $2 \pm 1$ & $83 \pm 16$ & $54 \pm 15$ & \lrcorner & $50 \pm 10$ & ] & & $161 \pm 87$ & $352 \pm 75$ \\
\hline
\end{tabular}



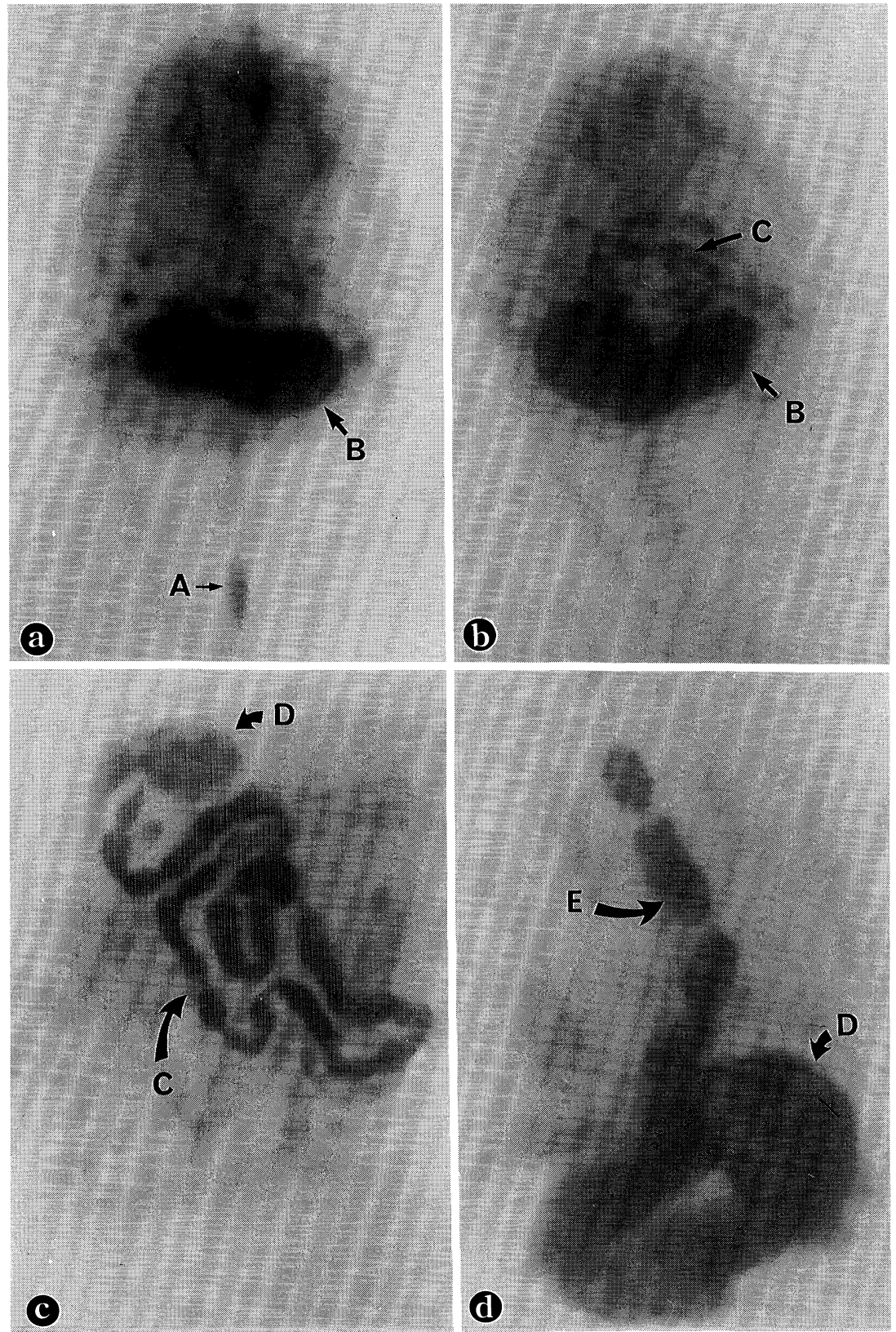

Fig. 1. $x$-Ray fluoroscopic images showing the transit of the barium medium through the digestive tract of a rat. After transit through the esophagus (A) (Fig. 1-a), the barium medium was retained in the stomach (B) for 2-3 minutes, and then expelled into the small intestine (C) (Fig. 1-b). The barium medium rapidly entered the cecum (D), where it remained (Fig. 1-c), and then entered the colon and assumed the shape of feces (E). The feces moved through the large intestine and were finally excreted by defecation (Fig. 1-d). 
A. Munakata et al.

TABLE 5. Gastrointestinal transit time in rats aged 16 months (Group D)

\begin{tabular}{|c|c|c|c|c|c|c|c|c|}
\hline \multirow{2}{*}{$\begin{array}{c}\text { Wheat bran } \\
(\%)\end{array}$} & \multicolumn{8}{|c|}{ Transit time (min) } \\
\hline & Stomach & $\begin{array}{c}\text { Small } \\
\text { intestine }\end{array}$ & Cecum & Colon & & & Rectum & Total \\
\hline $\begin{array}{c}0 \\
(n=13)\end{array}$ & $3 \pm 1^{a}$ & $111 \pm 14$ & $112 \pm 25$ & $110 \pm 16$ & & & $320 \pm 124$ & $656 \pm 103$ \\
\hline $\begin{array}{c}20 \\
(n=13)\end{array}$ & $2 \pm 1$ & $120 \pm 19$ & $100 \pm 21$ & $84 \pm 117$ & ** & $* *$ & $370 \pm 100$ & $677 \pm 90$ \\
\hline $\begin{array}{c}40 \\
(n=13)\end{array}$ & $2 \pm 1$ & $120 \pm 16$ & $96 \pm 14$ & $80 \pm 11$ & \rfloor & & $305 \pm 115$ & $603 \pm 120$ \\
\hline
\end{tabular}

colon transit time in the 20 and $40 \%$ diet groups $(84 \pm 11$ and $80 \pm 11 \mathrm{~min}$, respectively) was significantly shorter than that in the control diet group $(110 \pm$ $16 \mathrm{~min})(p<0.01)$.

The gastrointestinal transit time in Groups A and D (control diet) is shown in Fig. 2. All subunits of the transit time showed prolongation in association with the increased length throughout the entire digestive tract in the older rats, although the prolongation in the large intestine transit time, particularly the

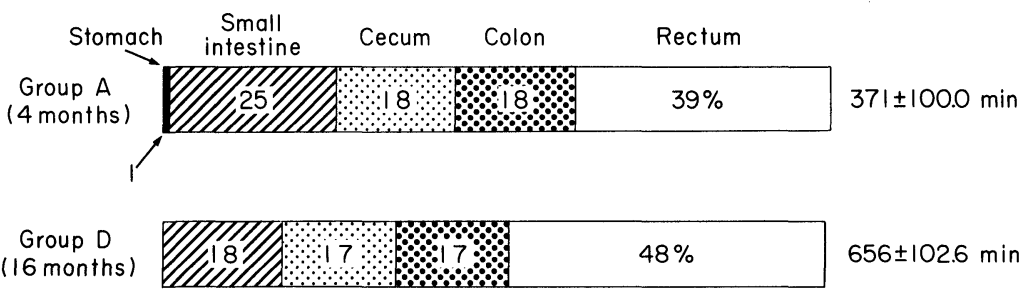

Fig. 2. Gastrointestinal transit time in rats in group $\mathrm{A}$ and $\mathrm{D}(0 \%$ diet) aged 4 and 16 months.

TABLE 6. Gastrointestinal transit time: basal diet (0\% wheat bran) in Groups $D, E$ and $F$

\begin{tabular}{ccccccc}
\hline & \multicolumn{5}{c}{ Transit time (min) } \\
\cline { 2 - 7 } Group & Stomach & $\begin{array}{c}\text { Small } \\
\text { intestine }\end{array}$ & Cecum & Colon & Rectum & Total \\
\hline $\begin{array}{c}\text { Group D } \\
(n=13)\end{array}$ & $3 \pm 1^{\mathrm{a}}$ & $111 \pm 14$ & $112 \pm 25$ & $110 \pm 16$ & $320 \pm 124$ & $656 \pm 103$ \\
$\begin{array}{c}\text { Group E } \\
(n=13)\end{array}$ & $2 \pm 1$ & $131 \pm 20$ & $95 \pm 14$ & $86 \pm 20$ & $308 \pm 97$ & $623 \pm 101$ \\
$\begin{array}{c}\text { Group F } \\
(n=13)\end{array}$ & $3 \pm 1$ & $109 \pm 15$ & $121 \pm 17$ & $107 \pm 20$ & $360 \pm 121$ & $699 \pm 91$ \\
\hline
\end{tabular}


rectum subunit, was more marked than that in the small intestine transit time.

There were no significant differences among Groups D, E and F in any subunit of the gastrointestinal transit time (Table 6).

Count, weight, water content and volume of feces

The results of feces analysis in Groups A, B and C are given in Table 7. As the wheat bran content of the diet increased, the number and volume increased, but the weight and water content per stool was constant regardless of the diet bran content.

\section{Fat absorption}

The daily fat excretion per gram of dried stools (Fig. 3) was the highest in the rats given the $15 \%$ pectin diet $(69.7 \pm 15.7 \mathrm{mg})$, followed by the rats given the non-fiber and $15 \%$ cellulose diets $(31.9 \pm 9.0 \mathrm{mg}$ and $9.8 \pm 0.3 \mathrm{mg}$, respectively). However, the total daily fat excretion was $134.6 \pm 13.7 \mathrm{mg}$ in the $15 \%$ pectin diet

TABLE 7. Number, weight, water content and volume of fecal pellets

\begin{tabular}{lccc}
\hline & \multicolumn{3}{c}{ Whear bran (\%) } \\
\cline { 2 - 4 } & 0 (Group A) & 20 (Group B) & 40 (Group C) \\
\hline Number of pellets (per 16 hr) & $19.6 \pm 4.2$ & $27.3 \pm 4.4^{* *}$ & $28.6 \pm 4.9^{* *}$ \\
Weight per pellet (g) & $0.34 \pm 0.16$ & $0.31 \pm 0.10$ & $0.33 \pm 0.10$ \\
Water content (\%) & $53.9 \pm 3.1$ & $54.4 \pm 2.0$ & $53.9 \pm 6.0$ \\
Volume per pellet $\left(\mathrm{cm}^{3}\right)$ & $0.20 \pm 0.06$ & $0.25 \pm 0.10^{* * *}$ & $0.29 \pm 0.13^{* * *}$ \\
\hline
\end{tabular}

${ }^{* *} p<0.01,{ }^{* * *} p<0.001$, compared with $0 \%$ wheat bran group

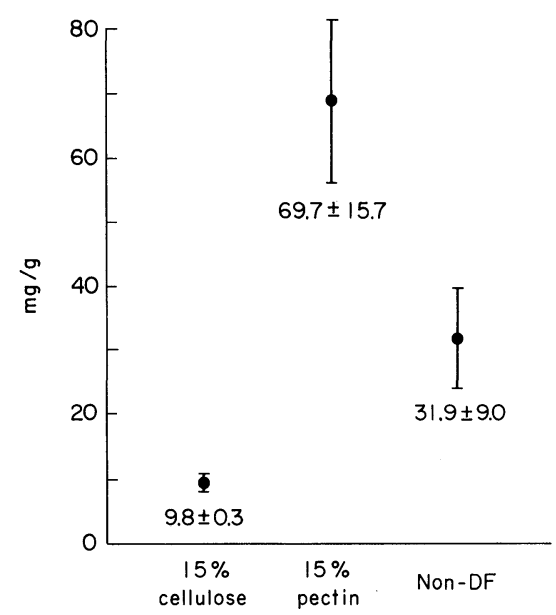

Fig. 3. Daily fat excretion per gram of dried stool. 


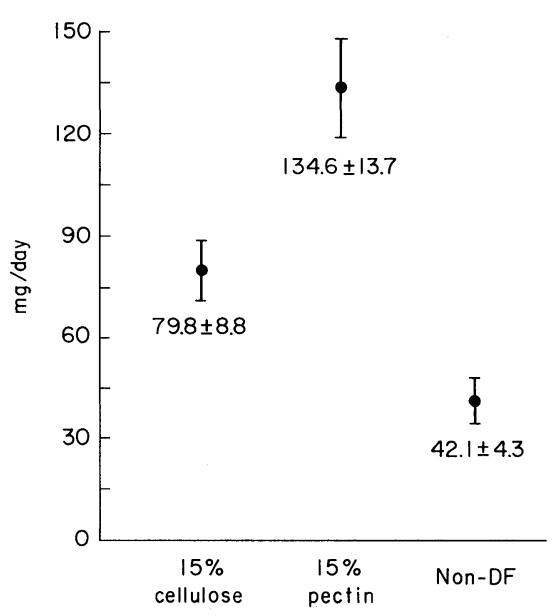

Fig. 4. Daily fat excretion.

group, $79.8 \pm 8.8 \mathrm{mg}$ in the $15 \%$ cellulose diet group, and $42.1 \pm 4.3 \mathrm{mg}$ in the non-fiber diet group (Fig. 4).

\section{Discussion}

Burkitt et al. (1972) suggested that the high incidence of colon diverticulosis and cancer in western Europe could be attributed to dietary lack of fiber, and noted that African peoples in whom these diseases are rare consumed a large amount of fiber and showed heavy fecal weight with markedly shortened gastrointestinal transit time. Iwane (1984) observed an inhibitory effect of wheat bran on the development of colorectal cancer in rats given diets containing 0,20 , or $40 \%$ wheat bran and intraperitoneally injected with 1,2-dimethylhydrazine. Their endoscopic observation of the large intestine revealed that the time until development of tumors was prolonged in the rats receiving the 20 and $40 \%$ fiber diets. Similar results have been reported by numerous researchers (Willson et al. 1977; Barbolt and Abraham 1978; Abraham et al. 1980; Bauer et al. 1981; Jacob 1983; Iwane 1989). Although it is controversial and experimental studies have varied in methodology and other factors, the concept that high fiber diet plays a protective role against the development of cancer in the large intestine has gained wide acceptance.

Various mechanisms have been proposed in the inhibitory action of dietary fiber on carcinogenesis in the large intestine (Payler et al. 1975; Walker 1975; Connel 1976; Cummings et al. 1976a, b; Baird et al. 1977; Mathe et al. 1977; Clinton et al. 1978; Cummings 1978; Kelsay 1978; Mickelson et al. 1979), including the following:

1) acceleration of excretion of carcinogenic substances by reduction of the gastrointestinal transit time (large intestine transit time) of food; 
2) increase of fecal weight and acceleration of absorption and dilution of carcinogens;

3) effects on bile acids (secondary bile acids, in particular), which are thought be carcinogenic;

4) effect in changing the large intestinal bacterial flora; and

5) relative decrease of intake of fat, which is believed to be closely related to carcinogenesis.

The mechanism of the inhibitory action of dietary fiber on the development of colon diverticulum, in contrast, is thought to be relatively more straightforward. Dietary fiber is assumed to shorten large intestine transit time, soften feces, increase fecal volume, and suppress the elevation of the internal pressure of the large intestine (Painter and Burkitt 1971). Alternatively, accumulation of fat in the serous membrane layer, particularly in the sites perforated by blood vessels, which are the most common sites of diverticula, is believed to increase the fragility of the intestinal wall (Shinohara 1955).

The large intestine transit time is thought to be the most important factor in these mechanisms. However, reliable transit time data have not yet been obtained, since there are no established methods of measuring this time.

The methods of measuring the gastrointestinal transit (retention) time of food are essentially of two types. In one type of technique, granules of radioactive substances which are not digested or absorbed are given to humans or animals, and the radioactivity of the excreted feces is determined. The period in which $50 \%$ or $80 \%$ of the administered radioactivity is excreted is regarded as the transit time (Hinton et al. 1969; Kirwan and Smith 1974). In the other, activated carbon, dyes, colored glass balls or capsules, which are also not digested or absorbed in the intestine, are given to humans or animals with food as a marker, and the period until excretion of the marker is measured (Kay and Truswell 1977). Measurement of hydrogen in expired gas is also performed to determine the time point at which food flows into the cecum. However, the large intestine transit time cannot be accurately determined by any of these methods.

In the present method, the fasting time is very long, and the experimental animal should be confined in a small space during measurement. Further, Kirwan and Smith (1974) and Hoelzel (1930) reported that the transit time is greatly influenced by the specific gravity of the intestinal content. Given these considerations, it is difficult to declare that the present method is physiologically reliable. However, this method does present the advantage that the time points at which the leading edge of the barium sulfate flows into the cecum and is excreted from the anus can be determined fairly accurately. Since barium sulfate is retained and forms a wide zone in the cecum, the time point of flow into the cecum is retrospectively determined by clearly differentiating the cecum. Because it takes only minutes to differentiate the organ, the measured time point is not subject to great error. The time point of excretion from the anus can be 
very clearly determined by observing movement of the anal sphincter at defecation. It is considered, therefore, that the present method can provide fairly accurate determination of the large intestine transit time, and that the data obtained are sufficiently reliable for transit time comparisons among different diet or age groups.

Consistent with many previous reports (Kay and Truswell 1977; Bond et al. 1978), the present study revealed that the gastrointestinal transit time (cecum and colon) tended to be shortened in rats receiving high fiber diet (high bran diet). This finding suggests that high fiber diet specifically shortens the large intestine transit time and is related to inhibition of development of diverticulum and carcinogenesis in the large intestine. However, since the transit time of the leading edge alone was measured in the present study, the status of contact between the mucous membrane of the large intestine and feces was not quantitatively evaluated. Further investigation of this question is required.

It has long been known and is widely reported that intake of high fiber diet increases fecal weight and softens feces. In this study, a greater number of feces pellets with larger volume and lower specific gravity was excreted by the rats receiving the diet containing high amount of bran. Such large soft feces contained a great amount of dietary fiber, which could be expected to exert its actions in adsorbing and diluting carcinogenic substances. The increase in fecal volume (weight) was also associated with reduced intestinal transit time of food. It is thought that the development of colorectal cancer, especially colon cancer, is suppressed by both of these mechanisms, and the development of colon diverticulum by the latter.

Fat has been suggested to accelerate the development of large intestine cancer in connection with bile acid and to promote the development of large intestine diverticulum in connection with obesity and accumulation of body fat. The present finding that dietary fiber suppresses the absorption of fat supports the hypothesis that dietary fiber inhibits the development of the two diseases.

\section{References}

1) Abraham, R., Barbolt, T.A. \& Rodgers, J.B. (1980) Inhibition by bran of the colonic carcinogenecity of bile salts in rats given dimethylhydrazine. Exp. Mol. Pathol., 33, 133-143.

2) Baird, I.M., Walters, R.L., Davies, P.S., Hill, M.J., Drase, B.S. \& Southgate, D.A.T. (1977) The effect of two dietary fiber supplements on gastrointestinal transit, stool weight and frequency, and bacterial flora, and fecal bile acids in normal subjects. Metabolism, 26, 117-128.

3) Barbolt, T.A. \& Abraham, R. (1978) The effect of bran on dimethylhydrazineinduced colon carcinogenesis in the rat. Proc. Soc. Exp. Biol. Med., 157, 656-659.

4) Bauer, H.G., Asp, N.G. \& Dahlqvist, A. (1981) Effect of two kinds of pectin and guar gum on 1,2-dimethylhydrazine initiation of the colon tumors and on fecal $\beta$-glucuronidase activity in the rat. Cancer Res., 41, 2518-2523.

5) Bond, J.H., Michael, D. \& Levitt, M.D. (1978) Effect of dietary fiber on intestinal 
gas production and small bowel transit time in man. Am. J. Clin. Nutr., 31, S169S174.

6) Burkitt, D.P. (1971) Epidemiology of cancer of colon and rectum. Cancer, 28, 313.

7) Burkitt, D.P., Walker A.R.P. \& Painter, N.S. (1972) Effect of dietary fiber in stools transit times, and its role in the causation of disease. Lancet, 2, 1408-1411.

8) Clinton, S.K., Truex, C.R. \& Visek, W.J. (1978) A model system for evaluating the role of dietary fiber in chemical carcinogenesis. Biochem. Pharmacol., 27, 1393-1396.

9) Connel, A.M. (1976) Natural fiber and bowel dysfunction. Am. J. Clin. Nutr., 29, 1427-1431.

10) Cummings, J.H. (1978) Dietary factors in the aetiology of gastrointestinal cancer. J. Human Nutr., 32, 455-60.

11) Cummings, J.H., Jenkins, D.J.A. \& Wiggins, H.S. (1976a) Measurement of the mean transit time of dietary residue through the human gut. Gut, 17, 210-218.

12) Cummings, J.H., Hill, M.J., Jenkins, D.J.A., Person, J.R. \& Wiggins, H.S. (1976b) Changes in fecal composition and colonic function due to cereal fiber. Am. J. Clin. Nutr., 29, 1468-1473.

13) Hinton, J.M., Lennard-Jones, J.E. \& Young, A.C. (1969) A new method for measuring gut transit using radio-opaque marker. Gut, 10, 842-847.

14) Hoelzel, F. (1930) The rate of passage of inert materials through the digestive tract. Am. J. Physiol., 92, 466-470.

15) Iwane, S. (1984) The effects of dietary fiber against 1, 2-dimethylhydrazine-induced colonic carcinogenesis in rats. J. Jpn. Soc. Colo-proct., 39, 536. (in Japanese)

16) Iwane, S. (1989) Endoscopic study on the effect of dietary fiber against 1, 2dimethylhydrazine-induced colonic carcinogenesis in rats. Jpn. J. Gastroenterol., 86, 2713-2720. (in Japanese)

17) Jacobs, LR (1983) Enhancement of rat colon carcinogenesis by wheat bran consumptioon during the stage of 1, 2-dimethylhydrazine administration. Cancer Res., 43, 4057-4061.

18) Kay, R.M. \& Truswell, A.S. (1977) Effect of citrus pectin on blood lipids and fecal steroides excretion in man. Am. J. Clin. Nutr., 30, 171-175.

19) Kelsay, J.L. (1978) A review of reserch on effects of fiber intake on man. $A m$. J. Clin. Nutr., 31, 142-159.

20) Kirwan, W.O. \& Smith, A.N. (1974) Gastrointestinal transit estimated by an isotope capsule. Scand. J. Gastroenterol., 9, 763-766.

21) Mathe, D., Lutton, C., Rautureau, J., Coste, T., Gouffer, E., Sulpice, J.C. \& Chevallier, F. (1977) Effects of dietary fiber and salt mixtures on the cholesterol metabolism of rats. J. Nutr., 107, 466-74.

22) Mickelson, O., Makdani, D.D., Cotton, R.H., Titcomb, S.T., Colney, J.C. \& Gatty, R. (1979) Effect of a high fiber bread diet on weight loss in college-age males. Am. J. Clin. Nutr., 32, 1703-1709.

23) Painter, N.S. \& Burkitt, D.P. (1971) Diverticular of the colon: A deficiency disease of Western civilization. Br. Med. J., 2, 450-454.

24) Payler, D.K., Pomare, E.W., Heaton, K.W. \& Harvey, R.F. (1975) The effect of wheat bran on intestinal transit. Gut, 16, 209-213.

25) Shinohara, S. (1955) A case of single diverticulum of the ascending colon. Clin. Gastroenterol., 3, 701-707. (in Japanese)

26) Van de Kamer, J.H. (1949) Rapid method for determination of fat in feces. J. Biol. Chem., 177, 347-351.

27) Van Soest, P.J. \& Wine, R.H. (1967) Use of detergents in analysis of fibrous feeds. IV. Determination of plant cell-wall consituents. J. Assoc. Off. Chem., 50, 50-55.

28) Walker, A.R.P. (1975) Effect of high crude fiber intake on transit time and the absorption of nutrients in South Africa Negro schoolchildren. Am. J. Clin. Nutr., 28, 
1161-1169.

29) Willson, R.B., Hutcheson, D.P. \& Wideman, L. (1977) Dimethylhydrazine-induced colon tumors in rats fed diets containing beef fat or corn oil with and without wheat bran. Am. J. Clin. Nutr., 30, 176-181. 